\title{
A expansão da pecuária para a Amazônia legal: externalidades espaciais, acesso ao mercado de crédito e intensificação do sistema produtivo
}

Cattle's expansion to the legal Amazon: spatial externalities, credit market access and intensification of production

Adirson Maciel de Freitas Junior (1)

Pedro Henrique Batista de Barros (1)

(1) Universidade de São Paulo

\section{Abstract}

This paper analyses the spatial distribution of the bovine herd in the Brazilian microregions between 1995 and 2016, especially in the Legal Amazon. From a spatial analysis with panel data, the growth rate showed to be between $5.6 \%$ to $15.68 \%$ higher in the Legal Amazon, while the increase in bovine density (herd per $\mathrm{km}^{2}$ ) was higher in $11.11 \%$ to $21.47 \%$, indicating a possible intensification of production in the region. In addition, there was a regional deconcentration of Brazilian livestock, especially due to positive spatial externalities that helped the spread of the herd. Credit for livestock also proved to be important to explain this growth by generating forces of attraction and propulsion for production. Specifically, the productivity of the inputs used in bovine nutrition (soybeans, corn and sugar cane) helped the growth of bovine density, but not in the herd, which corroborates its relationship with the intensification of production.

\section{Keywords}

cattle, Legal Amazon, spatial panel data.

JEL Codes Q13, R12, R14.

\section{Resumo}

Este trabalho analisa a distribuição espacial do rebanho bovino nas microrregiões brasileiras entre 1995 e 2016, com enfoque especial na Amazônia Legal. A partir de uma análise espacial com dados em painel, a taxa de crescimento do rebanho se mostrou entre $5,6 \%$ a $15,68 \%$ mais elevada na Amazônia Legal, enquanto o crescimento da densidade bovina (rebanho por $\mathrm{km}^{2}$ ) foi superior em $11,11 \%$ a $21,47 \%$, indicando uma possivel intensificação da produção na região. Além disso, verificou-se uma desconcentração regional da pecuária brasileira, em especial devido à presença de externalidades espaciais positivas que auxiliaram no espraiamento do rebanho. $O$ acesso ao crédito pecuário também se mostrou importante para explicar esse crescimento ao gerar forças de atração e propulsão para a produção. De maneira especifica, a produtividade dos insumos utilizados na nutrição bovina (soja, milho e cana-de-açúcar) auxiliou no crescimento da densidade bovina, mas não do rebanho, corroborando sua relação com a intensificação da produção.

\section{Palavras-chave}

pecuária, Amazônia Legal, análise espacial com dados em painel.

Códigos JEL Q13, R12, R14. 


\section{Introdução}

As atividades relativas à pecuária bovina no Brasil possuem grande importância, dado que o país tem o maior rebanho comercial do mundo, sendo o segundo maior produtor e o maior exportador mundial de carne bovina (Carvalho; Zen, 2017). O país figura, no cenário internacional, como um dos principais atores na produção e comércio de carne bovina, reflexo de um estruturado processo de desenvolvimento que elevou não só a produtividade como também a qualidade do produto brasileiro e, consequentemente, sua competitividade e abrangência de mercado. Nas últimas quatro décadas, a pecuária brasileira sofreu uma modernização sustentada por avanços no nível tecnológico dos sistemas de produção e na organização da cadeia produtiva, com reflexo na qualidade da carne bovina (EMBRAPA, 2017). Segundo Mcmanaus et al. (2016), esse rápido crescimento e modernização ocorreu principalmente na região Norte e Centro-Oeste do Brasil, especialmente a partir do início desse século.

No que se refere ao avanço da produção pecuária no Brasil, é visível uma divisão na literatura especializada. Alguns autores, como Cezar et al. (2005), Carvalho (2007), McManaus et al. (2016) e Silva et al. (2018) afirmam que o aumento na produção bovina no Brasil ocorreu principalmente devido à utilização do sistema de produção com base no regime de alimentação em pastagem. Desse modo, a expansão para áreas antes não ocupadas é uma importante ferramenta para a evolução da produção brasileira, sustentando a hipótese de um avanço da produção segundo um regime alimentar no formato extensivo. ${ }^{1}$ Por outro lado, autores como Fearnside (2005), Riveiro et al. (2009), e Assad (2016), afirmam que a bovinocultura avançou especialmente de forma intensiva ${ }^{2}$ a partir de um processo de desenvolvimento, integração e intensificação de sua produção, o que minimizou a abertura de novas áreas de pastagem. Em termos de rebanho, o efetivo mais que dobrou nas últimas quatro décadas, enquanto a área de pastagens não avançou na mesma proporção, indicando aumento da produtividade no período (Carvalho; Zen 2017).

Segundo Fearnside (2005), Riveiro et al. (2011) e Assad (2016), o crescimento apresentado pelo rebanho bovino brasileiro, a partir da década de

1 Regime alimentar exclusivo de pastagem.

2 Regime alimentar de pastagem com suplementação e confinamento. 
1990, se deu principalmente na região da Amazônia Legal. ${ }^{3}$ Nessa região, em especial, o rebanho aumentou, em grande medida, em virtude do aumento da área de pastos, aliado a ganhos de produtividade da pecuária fruto do sucesso do controle da febre aftosa, além de subsídios públicos. Entretanto, o crescimento da produção, em especial daquela advinda do aumento das pastagens, também gera externalidades ambientais negativas, principalmente devido ao desmatamento para abertura de novas áreas de produção.

Nesse contexto, este artigo tem como finalidade verificar a evolução e o desempenho da produção bovina nas microrregiões brasileiras, assim como os determinantes do crescimento apresentado no período de 1996 a 2016, com especial enfoque para a Amazônia Legal. Ademais, o trabalho buscará verificar se o rebanho bovino, assim como sua densidade, apresentou taxas de crescimento superiores em regiões, como a Amazônia, que inicialmente não possuíam grandes níveis de produção. Dito de outra forma, há um processo de desconcentração da produção pecuária brasileira? Basicamente, será considerado o nível da produção inicial das microrregiões em relação à sua posterior taxa de crescimento no período de análise, além de diversos fatores que possam ter induzido ao crescimento da produção pecuária, como a produtividade dos insumos básicos, área destinada ao plantio e montante de crédito rural para pecuária. Por fim, o número de cabeças de gado criadas nas microrregiões será utilizado como proxy para a produção pecuária brasileira. Isso possibilitará, portanto, a verificação de vinte anos de evolução espacial e temporal na produção bovina no Brasil.

Para se atingir os objetivos propostos, serão utilizadas as técnicas da Análise Exploratória de Dados Espaciais (AEDE), que permitem analisar a distribuição espacial, além de possíveis processos espaciais adjacentes, a saber, a existência de dependência e da heterogeneidade espacial. $\bigcirc$ uso dessas técnicas de análise espacial se deve ao fato de a agropecuária ser frequentemente sujeita aos efeitos espaciais citados, pois a existência de diferentes técnicas de produção, clima, topografia e condições de solo podem causar diferenças regionais significativas.

Ademais, muitos estudos que visam analisar fatores econômicos e agropecuários, utilizam-se de dados regionais, sendo, portanto, espaciais. Rondônia, Roraima e Tocantins) além de Mato Grosso e Maranhão. 
Entretanto, é comum a não consideração de possíveis efeitos espaciais contidos na amostra, o que pode invalidar as inferências estatísticas. Por esses motivos, além da AEDE e da estimação econométrica convencional de dados em painel, caso seja identificada a presença de dependência espacial, essa será devidamente considerada, adotando-se técnicas advindas da econometria espacial. Os procedimentos advindos das AEDE e da econometria espacial, portanto, possibilitarão o desenvolvimento de estimativas mais confiáveis, permitindo uma nova perspectiva da dinâmica espacial do crescimento do rebanho bovino brasileiro.

Sendo assim, o artigo se encontra estruturado em cinco seções, incluindo esta introdução. Na segunda será exposto o referencial teórico sobre a taxa de crescimento da produção bovina, especialmente sob a perspectiva brasileira, além da realização preliminar de um breve panorama sobre a produção no país. A terceira seção destina-se à descrição da metodologia, assim como da base de dados utilizada no trabalho. Os resultados encontrados e sua análise são realizados na quarta seção. Finalmente, na quinta seção têm-se as considerações finais.

\section{Fatores determinantes do crescimento do rebanho bovino brasileiro}

A produção bovina brasileira, com a incorporação de novas tecnologias que visam ao aumento da produtividade, de acordo com Carvalho (2007), cresceu especialmente devido à adoção de sistemas intensivos de produção. Na década de 1970, com auxílio do crédito rural, novas tecnologias foram incorporadas, como a importação de animais de raças europeias e indianas, da introdução de sal na alimentação; além da atenção especial dada ao controle de doenças como a febre aftosa. Desse modo, a partir de 1990, observou-se uma pecuária nacional com maiores índices de produtividade conjuntamente a uma indústria integrada nacionalmente.

O entendimento do sistema de produção bovino é importante para compreender a dinâmica de seu crescimento. Sendo assim, segundo a Cezar et al. (2005) e Kamali et al. (2016), a pecuária de corte brasileira apresenta uma ampla gama de sistemas de produção e é desenvolvida em todos os estados e ecossistemas do país. Além disso, há uma heterogeneidade nos sistemas produtivos, nos mecanismos de gestão e de comercialização 
do gado, sendo características importantes no desenvolvimento dessa atividade no Brasil.

No que se refere aos regimes alimentares adotados pelos pecuaristas brasileiros, coexistem basicamente três. $O$ primeiro é o de alta qualidade, caracterizado pela adoção de tecnologia avançada e padrões eficientes de gestão e de comercialização com o uso mais intensivo de pastagens cultivadas aliado à prática de confinamento na terminação. $O$ segundo, de baixa qualidade, baseia-se na produção extensiva, pequena intensidade tecnológica e padrões precários de gestão e de comercialização do gado bovino, que são caracterizados pela utilização de pastagens nativas e cultivadas como únicas fontes de alimentos energéticos e proteicos. Por fim, o terceiro e menos utilizado na produção pecuária, é o sistema semi-intensivo, que também apresenta como base alimentar as pastagens (nativas e cultivadas) e os suplementos minerais, acrescidos de suplementos proteicos/energéticos (Cezar et al., 2005)

A partir do regime alimentar adotado, é possível observar o aumento no consumo de subprodutos agroindustriais, segundo Filho (2001), visando usufruir da sazonalidade do boi gordo. Por isso, um número considerável de pecuaristas passara a manter seus animais, no último período de engorda, em sistemas intensivos, principalmente no confinamento. Tal procedimento possibilita o aumento no giro do capital, dadas a redução no tempo para a obtenção do boi gordo e a possibilidade de utilização de subprodutos agroindustriais na alimentação desses animais, como o bagaço hidrolisado da cana, grãos de soja e milho.

De acordo com Martinelli e Filoso (2008), Mendonça et al. (2016) e Carvalho e Zen (2017), subprodutos agroindustriais são amplamente utilizados na nutrição bovina, especialmente no regime alimentar de alta qualidade. Por isso, ao avaliar a produção pecuária, os autores afirmam que é necessário analisar e considerar o comportamento da produção de tais culturas, assim como suas respectivas produtividades, pois estas podem impactar diretamente a evolução da densidade bovina regional. Dito de outra forma, a alta produtividade dessas culturas em regiões próximas à produção pecuária pode induzir indiretamente o aumento do rebanho bovino. Conforme destaca Cezar et al. (2005), a produtividade da pecuária está associada basicamente ao sistema de produção intensivo, tornando, portanto, o regime alimentar um indicativo de seu aumento. Destaca-se, por exemplo, o crescimento do consumo de suplementos alimentares com 
o aumento da utilização subprodutos dos grãos de soja, milho e da cana de açúcar utilizada como volumoso. ${ }^{4}$

Outro fator importante para o avanço da produção bovina no Brasil é a disponibilidade de crédito. Avanços na política de expansão do crédito para a pecuária são fundamentais no processo de modernização da bovinocultura do país, sendo eles oriundos de financiamentos do PRONAF (Programa Nacional de Fortalecimento da Agricultura Familiar). Entretanto, o credito pecuário é distribuído de forma desigual ao longo do território brasileiro, além de algumas regiões receberem valores mais elevados para custeio ${ }^{5}$ enquanto em outras há predominância de investimentos ${ }^{6}$ (Macedo, 2005).

Porém, vale ressaltar que o crescimento da agropecuária e especialmente da pecuária bovina no Brasil veio acompanhado do desmatamento dos três principais biomas brasileiros: a Mata Atlântica, o Cerrado e a Amazônia. A Mata Atlântica sofreu mais degradação devido à agricultura, à expansão da urbanização e, em menor grau, da pecuária, sendo que atualmente a maior parte desse bioma permanece em fragmentos, localizados no litoral, Serra do Mar e nas encostas da Serra Geral. O bioma Cerrado foi substituído principalmente por pasto e/ou outros cultivos diversos, como a soja. E, por fim, na Amazônia, a ocupação ocorreu principalmente pela incorporação de novas áreas de produção agropecuária, especialmente da pecuária, nas áreas da fronteira agrícola da região. Além disso, nas últimas décadas, esse bioma tem sofrido grande pressão para o aumento da produção pecuária (Alencar et al., 2015; Domingues, 2017).

Carvalho (2007) e Martinelli et al. (2010) também enfatizam que a pecuária bovina de corte se desenvolveu, nas últimas décadas, principalmente devido à expansão da fronteira agrícola na Amazônia, com a incorporação de novas terras. Segundo Barona et al. (2010), o avanço do desmatamento na Amazônia pode estar ligado especialmente à produção da pecuária e, em menor grau, da soja; devido à pressão que essas exercem nas áreas de

4 Suplementação para gado de corte em confinamento. Alimentos volumosos são basicamente aqueles que têm alto teor de fibra e baixo valor energético, geralmente utilizados para produção de silagem.

5 O PRONAF Custeio: aquisição de sementes, fertilizantes, defensivos, vacinas, ração e outros itens necessários para o dia a dia da sua produção, seja ela agrícola ou pecuária (PRONAF, 2018). 6 O PRONAF Investimento: financiar despesas de produção, investir em benfeitorias, tratores, máquinas e implementos agrícolas, além de comercializar a produção. As soluções de crédito rural contribuem para a diminuição de custos, aumento da produtividade e melhoria no fluxo de caixa, e capital de giro para atividade agropecuária (PRONAF, 2018). 
florestas próximas à fronteira agrícola. De fato, segundo Silva et al. (2018), a expansão da pecuária na região amazônica tem como consequência direta uma maior pressão sobre o meio ambiente, refletida na diminuição das áreas de florestas primárias. Além disso, o crescimento da produção pecuária na região gerou diversas mudanças socioambientais no uso da terra, agravadas pela baixa capacidade de suporte das pastagens na região, assim como o baixo nível tecnológico dos sistemas de produção desenvolvidos. Por fim, segundo Brondizio (2009), o aumento do desmatamento na região se deve, em grande medida, aos incentivos dados pelo crédito rural destinado aos produtores.

O avanço do rebanho bovino na Amazônia Legal pode ser evidenciado, por exemplo, pelo número de cabeças de gado na região. Em 1995, por exemplo, havia 37 milhões de cabeças na região, valor equivalente a $23 \%$ do total nacional. Em 2016, por outro lado, esse valor saltou para $85 \mathrm{mi}$ lhões - cerca de $40 \%$ da produção brasileira. Nascimento (2017) destaca que o aumento da pastagem para a criação de gado é a atividade que mais contribui para o desmatamento na Amazônia, compreendendo 65\% dessa área desmatada. Uma série de estudos vem apontando para os impactos negativos de práticas agropecuárias nos desmatamentos na Amazônia, em especial, no que se refere às atividades ligadas à criação de bovinos, que possivelmente geram maiores impactos ambientais do que outras atividades (Brondizio, 2009; Alencar et al. 2015).

Nesse sentido, o presente artigo buscar contribuir com a discussão sobre a evolução do rebanho bovino brasileiro, com especial enfoque para a Amazônia Legal. Isso será realizado com a estimação de um modelo econométrico visando verificar a consistência do avanço da produção bovina no Brasil. Para tanto, na seção seguinte será apresentada uma discussão sobre a metodologia adotada e a base de dados utilizada.

\section{Metodologia}

\subsection{Base de dados e mecanismos metodológicos}

A variável básica considerada é o número de cabeças de bovinos nas 588 microrregiões brasileiras no período entre 1995 e 2016, tendo como base de dados a Pesquisa Pecuária Municipal (PPM), extraída do Sistema de Re- 
cuperação Automática (SIDRA) do Instituto Brasileiro de Geografia e Estatística (IBGE). A utilização do número de cabeças de gado será utilizada para captar o desenvolvimento espaçotemporal da produção pecuária brasileira ao longo de suas regiões do país. Também serão empregadas variáveis referentes à produtividade do milho, soja e cana-de-açúcar. ${ }^{7}$ Segundo Martinelli e Filoso (2008), Mendonça et al. (2016), Carvalho e Zen (2017), para caracterizar o sistema intensivo de produção, em caso da inexistência de dados específicos, é coerente utilizar como proxy a produtividade dos subprodutos agrícolas, insumos básicos para a produção em sistemas intensivos de produção. Ao reduzir o custo dessas matérias-primas, pode-se induzir a adoção desses insumos pela pecuária, intensificando a produção. Portanto, o presente trabalho busca contribuir com literatura no que se refere à discussão da produtividade das culturas utilizadas na alimentação bovina, principalmente na utilização desses insumos no sistema intensivo de engorda e seus efeitos na produção bovina.

Entretanto, a produtividade dos insumos tende a apresentar valores semelhantes para a mesma microrregião devido à semelhança de características físicas, naturais e humanas dessas localidades, resultando em colinearidade entre as variáveis. Para minimizar o problema, será construído um indicador de produtividade a partir da estatística multivariada, especialmente da análise fatorial. Essa técnica possibilitará evitar o viés de má especificação do modelo, ao mesmo tempo que trata o problema de multicolinearidade, pois o método permite sintetizar as variáveis em fatores ortogonais e não correlacionados entre si, melhorando o ajuste do modelo. A extração dos fatores será realizada por meio do método de componentes principais, relacionando linearmente as $Z_{i}$ variáveis e os $k$ fatores comuns extraídos, conforme:

$$
\begin{aligned}
& Z_{1}=l_{11} F_{1}+\ldots+l_{1 k} F_{k}+\varepsilon_{1} \\
& \vdots \\
& Z_{p}=l_{p 1} F_{p}+\ldots+l_{p k} F_{k}+\varepsilon_{p}
\end{aligned}
$$

ou matricialmente por:

$$
D(X-\mu)=L F+\varepsilon
$$

7 Rendimento médio da produção (quilogramas por hectare). 
onde $F$ é um vetor aleatório contendo $k$ fatores, que resume as $p$ variáveis incluídas; $\varepsilon$ é um vetor de erros aleatório, que contém a parcela de $Z_{i}$ não explicada pelos $F_{j}$ fatores, com $j=1,2, \ldots, k \in \mathbb{N} ; L$ é uma matriz de parâmetros $l_{i j}$ (loadings) a serem estimados, os quais representarão o grau de relação linear entre $Z_{i}$ e $F_{j}$. De posse do fator produtividade de insumos, ${ }^{8}$ será testada a hipótese de que regiões com alta produtividade das culturas consideradas impactam positivamente no crescimento do rebanho bovino.

Outra variável importante, que visa captar mudanças estruturais das microrregiões, é a área total da microrregião destinada ao plantio. As variáveis de produtividade e área plantada provêm da Pesquisa Pecuária Municipal (PPM), extraídas do Sistema de Recuperação Automática (SIDRA) do IBGE. Também serão utilizados dados para o montante de crédito pecuário destinado à microrregião, variável extraída do Instituto de Pesquisa Econômica Aplicada (IPEA) e Banco Central do Brasil. Por fim, para investigar se a região Amazônica teve uma taxa de crescimento diferenciada em relação às demais localidades do país, uma variável dicotômica para a Amazônia Legal será incluída no modelo utilizado, a qual caberá maiores explicações nos próximos parágrafos. Em síntese, as variáveis utilizadas no presente artigo estão descritas no Quadro 1.

Quadro 1 Variáveis utilizadas

\begin{tabular}{l|l|l}
\hline Variável & Descrição & Fonte \\
\hline Rebanho bovino & Número de cabeças de gado. & IBGE \\
\hline Densidade bovina & Número de cabeças de gado dividido pala área da região $\left(\mathrm{km}^{2}\right)$. & IBGE \\
\hline $\begin{array}{l}\text { Produtividade } \\
\text { dos insumos }\end{array}$ & Fator criado por meio da análise fatorial. & IBGE \\
\hline Área do plantio & Área plantada em hectares. & IBGE \\
\hline Crédito pecuário & $\begin{array}{l}\text { Financiamentos concedidos a produtores e cooperativas desti- } \\
\text { nados ao custeio e investimento na pecuária. }\end{array}$ & $\begin{array}{l}\text { IPEA e Ban- } \\
\text { co Central }\end{array}$ \\
\hline Dummy Amazônia & Variável dicotômica para Amazônia Legal. & - \\
\hline
\end{tabular}

Fonte: Elaboração própria.

De posse desse banco de dados, efetuou-se uma média de dois anos para representar cada unidade de cross section que irá compor o painel de da-

8 A aplicação da análise fatorial para criar o fator de produtividade de insumos possibilitou sintetizar as três variáveis em apenas um fator com um valor de 0,5795 para o teste Kaiser-Meyer-Olkin (KMO), 1,71 de carga fatorial e 57,06\% de variância acumulada. 
dados. ${ }^{9}$ O procedimento é comumente adotado com a finalidade de se minimizar efeitos aleatórios, como o de variações de preços, climáticas, entre outros, que podem afetar o crescimento do rebanho. Entretanto, essas flutuações, muitas vezes, não representam a dinâmica da pecuária brasileira. Para verificar o comportamento do crescimento do rebanho e a densidade bovina na região Amazônia, será adotado um procedimento metodológico proposto por Wooldridge (2002), que se caracteriza como uma forma de se incluir variáveis dicotômicas no contexto de dados em painel. Primeiramente, criou-se uma variável temporal $(t)$ para os quatro períodos analisados e uma dummy que assume 1 para a microrregião pertencente à Amazônia Legal e 0 para as demais. Por fim, estabeleceu-se uma dummy de interação entre elas, resultando, portanto, numa variável representativa da Amazônia Legal para cada período. De forma geral, o resultado pode ser formalizado como

$$
y_{i t}=\alpha+\theta_{i t}+\beta_{1} X_{i t}+\beta_{t} \text { AmazoniaLegal }+\varepsilon_{i t}
$$

em que $X$ é o vetor de variáveis explicativas para a microrregião $i$ no período $t ; \theta$ é a heterogeneidade não observada. O procedimento busca isolar o efeito temporal das microrregiões pertencentes à Amazônia Legal com a finalidade de identificar se a taxa de crescimento do rebanho e da densidade bovino apresenta alguma dinâmica diferenciada nessa região em relação às demais localidades. Portanto, o modelo básico específico a ser estimado pelo presente artigo pode ser representado como

$$
\begin{aligned}
& \ln \frac{\left(\text { Rebanho.Bov }_{i, t}\right)}{\left(\text { Rebanho.Bov }_{i, t-1}\right)}=\alpha+\theta_{i t}+\beta_{1} \ln \left(\text { Rebanho.bov }_{i, t-1}\right)+ \\
& +\delta \ln \left(\text { CEM }_{i, t-1}\right)+\beta_{t} \text { AmazôniaLegal }+\varepsilon_{i, t}
\end{aligned}
$$

e

$$
\begin{aligned}
& \ln \frac{\left(\text { Densidade.Bov }_{i, t}\right)}{\left(\text { Densidade.Bov }_{i, t-1}\right)}=\alpha+\theta_{i t}+\beta_{1} \ln \left(\text { Densidade.bov }_{i, t-1}\right)+ \\
& +\delta \ln \left(C E M_{i, t-1}\right)+\beta_{t} \text { AmazôniaLegal }+\varepsilon_{i, t}
\end{aligned}
$$

9 Por exemplo, o primeiro período será composto pela média dos anos de 1995 e 1996. 
onde $\ln \frac{\left(\text { Rebanho.Bov }_{i, t}\right)}{\left(\operatorname{Rebanho.Bov}_{i, t-1}\right)}$ e $\ln \frac{\left(\text { Densidade.Bov }_{i, t}\right)}{\left(\text { Densidade.Bov }_{i, t-1}\right)}$ é o logaritmo natural da razão entre o rebanho e a densidade bovina, respectivamente, no período $t$ pelo rebanho em $t-1$ e pode ser interpretada como a taxa de crescimento da produção e densidade pecuária na microrregião $i ; \beta \operatorname{In}\left(\right.$ Rebanho.bov $v_{i, t-1}$ ) e $\beta$ In (Densidade.bov ${ }_{i, t-1}$ ) é o logaritmo natural do rebanho e densidade bovina no período inicial $t-1 ; \varepsilon_{i}$ é o termo de erro. Sendo que a hipótese de desconcentração do rebanho no território nacional é determinada pelo sinal do parâmetro $\beta_{1}$ : se esse for negativo e significativo, o processo se confirma. Por fim, $C E M_{i, t-1}$ se refere a um vetor de variáveis de controle, que busca representar as características estruturais da microrregião $i$ no período $t-1$, sendo composto pelas seguintes variáveis: área total destinada ao plantio; crédito pecuário total e o indicador de produtividade dos insumos. A defasagem temporal das variáveis de controle busca evitar problemas de endogeneidade na estimação. As variáveis para a Amazônia Legal ${ }^{10}$ se referem às dummys para o período entre 1995 e 2016.

\subsection{Análise Exploratória de Dados Espaciais (AEDE) e Análise Espa- cial com Dados em Painel}

As técnicas advindas da Análise Exploratória de Dados Espaciais utilizadas neste trabalho para identificar efeitos espaciais, especificamente os de dependência e heterogeneidade espacial, foram o I de Moran global e o local. O primeiro capta o grau de correlação espacial de uma variável através das regiões,

$$
I_{t}=\left(\frac{n}{s_{0}}\right)\left(\frac{z_{t}^{\prime} w_{z t}}{z_{t}^{\prime} z_{t}}\right)
$$

onde $W$ pode ser definida como uma matriz quadrada em que cada célula $w_{i j}$ indica relação existente entre a região $i$ e $j$ em um sistema de $n$ regiões; o termo $S_{0}$ é um escalar igual à soma de todos os elementos de $W$. $\mathrm{O}$ indicador acima é equivalente ao grau de associação linear entre o vetor

10 Para evitar a armadilha da variável dummy, excluiu-se a variável para o primeiro período, 1995. 
de valores observados, $z$, e a média ponderada de valores vizinhos, $W_{z}$. A versão local do I de Moran, por sua vez, é

$$
I_{t}=z_{i} \sum_{j-1}^{j} w_{i j} z_{j}
$$

onde $z_{i}$ representa a variável de interesse da região $i$ padronizada, $w_{i j}$ é o elemento da matriz de ponderação espacial (W) e $z_{j}$ é o valor da variável de interesse na região $j$ padronizada, podendo representar quatro tipos de clusters espaciais: Alto-Alto (AA), Baixo-Baixo (BB), Alto-Baixo (AB) e Baixo-Alto (BA). O cluster Alto-Alto, por exemplo, captura regiões com alto valor que estejam circundadas por outras com valores similares.

O método utilizado para investigar os determinantes do crescimento da produção bovina brasileira será o de painel de dados espacial. Tal escolha se deve ao fato de a produção bovina não estar, ao longo do período, relacionada simplesmente com os fatores explicitamente incluídos na regressão, mas também com características próprias de cada microrregião. O método de dados em painel possibilita captar esses efeitos fixos não observáveis que iriam, caso contrário, compor o termo de erro, enviesando as estimativas quando correlacionadas com as variáveis explicativas. A utilização da regressão com dados em painel tem como objetivo minimizar o viés e tornar o modelo consistente, ou seja, simétrico e com menor variância possível.

Entretanto, um dos pressupostos do modelo de dados em painel é que as unidades de corte transversal são independentes entre si. Segundo Almeida (2012), ao se investigarem unidades espaciais, como as microrregiões, há grande probabilidade de a amostra apresentar autocorrelação espacial, especialmente ao se tratar de atividade economicas como a pecuária, que usualmente se concentra espacialmente, o que exige a incorporação desse efeito no modelo no sentido de evitar problemas advindos de omissão de variável relevante. Além disso, para efeitos de comparação, serão estimados os modelos espaciais por meio de efeito fixo (fixed effect-FE) e de efeito aleatório (random effect-RE). Posteriormente, o teste de Hausman espacial será realizado para identificar qual modelo é o mais adequado para conjunto de dados. Por fim, o critério de informação de Akaike será empregado para verificar a qualidade do ajuste dos modelos, considerando o melhor modelo aquele que apresentar o menor valor.

No presente artigo, serão estimados basicamente três modelos, conside- 
rando uma matriz de peso espacial $n \times n, W$, para cada período $t=1, \ldots, T$, um vetor $n \times 1$ da variável dependente, $y_{t}$ e $X_{t}$ como uma matriz $n \times n$ de regressores. $O$ primeiro modelo será o Spatial Autoregressive Model (SAR):

$$
y_{t}=\rho W y_{y}+X_{t} \beta+\mu+\varepsilon_{t} \quad t=1, \ldots, T
$$

onde $\mu \sim N\left(0, \sigma_{\mu}^{2}\right)$ se efeitos aleatórios, enquanto $\mu$ é um vetor de parâmetros se estimado por efeitos fixos. As hipóteses-padrão sobre o modelo são que $\epsilon_{i t} \sim N\left(0, \sigma_{\epsilon}^{2}\right)$ e $E\left(\epsilon_{i t} \epsilon_{j s}\right)=0$ para $i \neq j$ e/ou $t \neq s$. O Spatial Error Model (SEM) foca na autocorrelação espacial no termo de erro,

$$
\begin{aligned}
& y_{t}=X_{t} \beta+\mu+v_{t} \\
& v_{t}=\lambda M v_{t}+\varepsilon_{t}
\end{aligned}
$$

em que $M$ é a matriz de pesos espaciais que pode ser ou não igual a $W$. Por fim, o Spatial Durbin Model se caracteriza como uma generalização do modelo SAR, mas com a adição de variáveis independentes defasadas espacialmente como variáveis explicativas,

$$
y_{t}=\rho W y_{t}+X_{t} \beta+W Z_{t} \theta+\mu+\varepsilon_{t}
$$

É possível que $Z_{t}=X_{t}$. A estimação dos referidos modelos adotará o método de Máximo Verossimilhança.

\section{Resultados}

Uma análise descritiva prévia dos dados foi realizada com a finalidade de verificar a dinâmica apresentada pelo rebanho bovino brasileiro. Em 1990, o Brasil possuía aproximadamente 151 milhões de cabeças enquanto, em 2015 , esse número aumentou para 215 milhões, um crescimento de 42,38\% em 25 anos, uma taxa dea 1,69\% ao ano. Entretanto, autores como Carvalho e Zen (2017) e Nascimento (2017) sustentam que tal crescimento não aconteceu de forma homogênea ao longo do território nacional. Quando se consideram níveis regionais, por exemplo, de acordo com Rodrigues et al. (2018), "o rebanho bovino nos estados da Amazônia Legal 
brasileira saltou de 26,2 milhões de cabeças em 1990 para 80,7 milhões de cabeças em 2013, um acréscimo de 207,38\% no efetivo, sendo que os estados de Mato Grosso e Pará, juntos, corresponderam por quase $60 \%$ desta variação - 32,3 milhões de cabeças adicionais nos dois estados no mesmo período". Fica evidente, portanto, um expressivo aumento do tamanho do rebanho bovino na Amazônia Legal. Para verificar esse processo em nível local, as Tabelas 1 e 2 trazem as dez microrregiões com maior número de cabeças no ano de 1990 e 2015, respectivamente. A finalidade é investigar a existência de alterações significativas entre as principais regiões produtoras do país, além de verificar como o crescimento do rebanho na Amazônia Legal alterou a disposição das microrregiões.

Tabela 1 Número de cabeças por microrregião em 1990

\begin{tabular}{lrrrr}
\hline Município & \multirow{2}{*}{ UF } & & Ano 1990 \\
\cline { 3 - 4 } & & Cabeças & Participação \\
\hline Sudoeste de Goiás & GO & 2.913 .789 & $1,93 \%$ \\
\hline Três Lagoas & MS & 2.675 .005 & $1,77 \%$ \\
\hline Dourados & MS & 2.605 .707 & $1,72 \%$ \\
\hline Baixo Pantanal & MS & 2.255 .665 & $1,49 \%$ \\
\hline Iguatemi & MS & 2.249 .591 & $1,49 \%$ \\
\hline Campo Grande & MS & 2.137 .203 & $1,41 \%$ \\
\hline Campanha Ocidental & RS & 2.018 .477 & $1,34 \%$ \\
\hline Alto Taquari & MS & 1.882 .199 & $1,25 \%$ \\
\hline Frutal & MG & 1.743 .124 & $1,15 \%$ \\
\hline Rio Vermelho & GO & 1.682 .443 & $1,11 \%$ \\
\hline Total & & 22.163 .203 & $14,66 \%$ \\
\hline
\end{tabular}

Fonte: Resultado da pesquisa.

Por meio da Tabela 1, constata-se que, em 1990, as microrregiões com maior número de cabeças estavam, em sua maioria, localizadas na região Centro-Oeste do país, excetuando-se uma microrregião localizada no Rio Grande do Sul, com nenhuma representante da Amazônia Legal. Teixeira e Hespanhol (2006) apontam que a alta produção no Centro-Oeste se deve a uma acelerada modernização pela qual passou a região na década de 1970, especialmente incentivada por aumento na concessão de crédito para a realização de investimentos. Por fim, o somatório do estoque bovino das dez maiores microrregiões produtoras resulta em $14,66 \%$ do total nacional. 
Nota-se, na Tabela 2, que apenas três das microrregiões que estavam no grupo das dez maiores produtoras em 1990, mantiveram-se entre as maiores em 2015. Desse modo, é evidente um deslocamento da produção bovina no Brasil, com uma mudança substancial na localização dos maiores rebanhos. Ademais, é evidente o avanço de microrregiões localizadas na Amazônia Legal, que passaram a contar com a maioria das microrregiões em 2015. Os números aqui apresentados corroboram, portanto, as hipóteses sustentadas por Carvalho (2007), Martinelli et al. (2010) e Alencar et al. (2015), que identificaram na região amazônica o principal vetor de atração da produção bovina no país nas últimas décadas. Dessa forma, confirma-se o deslocamento da produção pecuária do bioma Cerrado para o Amazônico, conforme destacado por Rodrigues et al. (2018).

Tabela 2 Número de cabeças por microrregião em 2015

\begin{tabular}{lrrrr}
\hline Município & \multirow{2}{*}{ UF } & & Ano 2015 \\
\cline { 3 - 4 } & & Cabeças & Participação \\
\hline São Félix do Xingu* & PA & $3.702 .134,3$ & $1.57 \%$ \\
\hline Três Lagoas & MS & $3.250 .585,3$ & $1.72 \%$ \\
\hline Aripuanã* & MT & $3.142 .870,3$ & $1.36 \%$ \\
\hline Alto Taquari & MS & $2.984 .822,3$ & $1.27 \%$ \\
\hline Norte Araguaia* & MT & $2.951 .275,0$ & $1.49 \%$ \\
\hline Ji-Paraná* & RO & $2.864 .048,7$ & $1.30 \%$ \\
\hline Porto Velho* & RO & $2.702 .160,3$ & $1.04 \%$ \\
\hline Sudoeste de Goiás & GO & $2.517 .513,0$ & $1.24 \%$ \\
\hline Baixo Pantanal & MS & $2.493 .588,7$ & $1.24 \%$ \\
\hline Alta Floresta* & MT & $2.432 .865,7$ & $1.17 \%$ \\
\hline Total & & $29.041 .863,7$ & $13,39 \%$ \\
\hline
\end{tabular}

Fonte: Resultado da pesquisa.

Nota: * Microrregiões pertencentes à Amazônia Legal.

Outro ponto importante a ser destacado é a ocorrência de uma desconcentração da produção, com as principais regiões produtoras passando de $14,66 \%$ do total para $13,39 \%$. Apesar de o número de cabeças pertencentes às principais microrregiões terem aumentado de 22.163.203 para 29.041.8653, sua representação no total diminuiu, indicando que as outras regiões apresentaram taxas de crescimento superiores. Para melhor observar a evolução e distribuição da produção bovina no Brasil ao longo do 
período de análise, foram construídos três mapas de quantile (Figura 1). O primeiro, da esquerda para a direita, refere-se ao estoque de gado nas microrregiões em 1990 enquanto o segundo é para 2015 e o terceiro mostra a taxa de crescimento entre os períodos. Fica evidente que, em 1990, os maiores produtores se localizavam especialmente no Centro-Oeste do país. Por outro lado, em 2015, verifica-se uma distribuição mais igualitária entre as microrregiões, indicando um possível processo de desconcentração do rebanho bovino ao longo do território brasileiro, em especial devido ao aumento da produção nas microrregiões pertencentes à Amazônia Legal.

Figura 1 Rebanho bovino nas microrregiões brasileiras (1990 e 2015) e a taxa de crescimento no período

a) $1990^{*}$

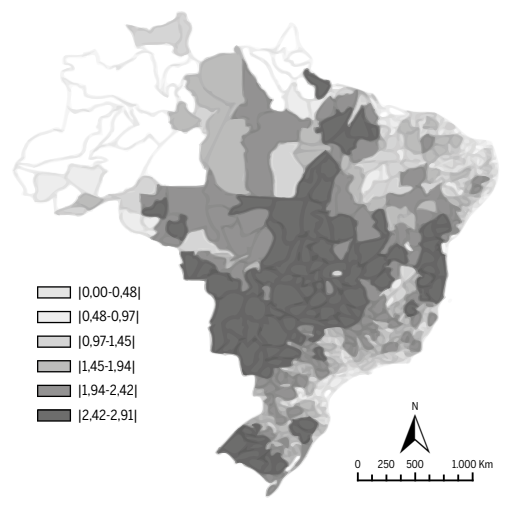

b) $2015^{*}$

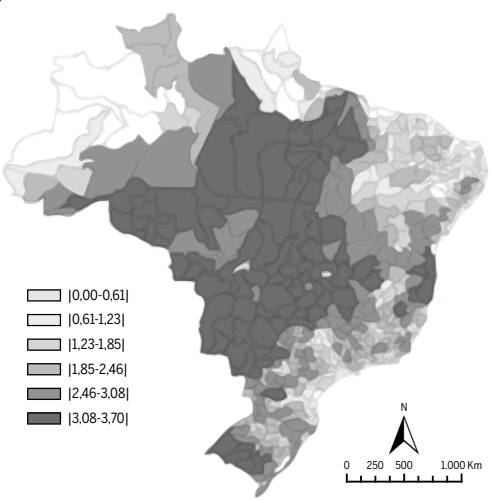

c) $1990 / 2015^{* *}$

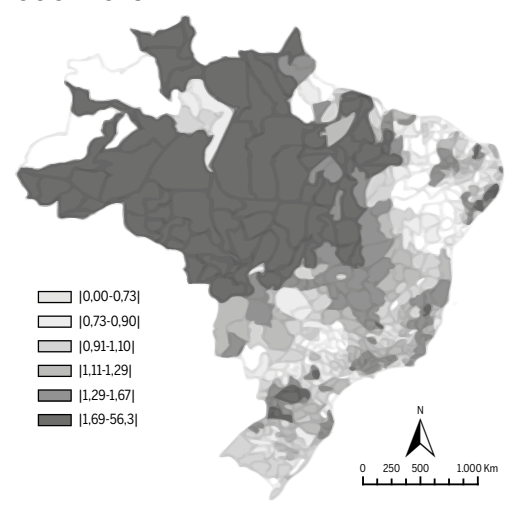

Fonte: Elaboração própria.

Nota: * Em milhões de cabeças, ${ }^{* *}$ Taxa de crescimento em termos percentuais (\%). 
As regiões localizadas na Amazônia Legal apresentaram taxas de crescimento mais elevadas do que as demais, fato que evidencia o processo de avanço da produção bovina para essa região. Conforme salienta Dias Filho (2011), diversos elementos foram responsáveis para o avanço da pecuária na fronteira agrícola da Amazônia, destacando-se a abertura de estradas, o estabelecimento de incentivos fiscais e crédito rural subsidiado. Fatores que visavam ao desenvolvimento socioeconômico da região, assim como condições climáticas adequadas, com temperaturas mais uniformes e períodos de estiagem relativamente menos severos e extensos que em outras regiões do país. Ademais, é visível a concentração espacial do rebanho em ambos os anos, assim como da taxa de crescimento. Isso é comprovado por meio da estatística I de Moran da Tabela 3, cujos valores são positivos e estatisticamente significativos independentemente da matriz de convenção aplicada. Portanto, microrregiões com elevado rebanho e taxa de crescimento tenderam a estar rodeados também por regiões com altos valores (e vice-versa). Além disso, observa-se aumento na magnitude dos coeficientes, sinalizando uma intensificação da concentração espacial.

Tabela 3 I de Moran para o rebanho brasileiro em 1990, 2015 e para a taxa de crescimento no período

\begin{tabular}{l|c|c|c|c}
\hline \multirow{2}{*}{ Município } & \multicolumn{3}{r}{ Matriz de convenção } \\
\cline { 2 - 5 } & Três viz. & Cinco viz. & Sete viz. & Dez viz. \\
\hline Rebanho bovino 1990 & $\mathbf{0 , 5 8 3 9 ^ { * }}$ & $0,5467^{*}$ & $0,5256^{*}$ & $0,4814^{*}$ \\
\hline Rebanho bovino 2015 & $\mathbf{0 , 6 4 8 0 ^ { * }}$ & $0,6188^{*}$ & $0,6225^{*}$ & $0,5584^{*}$ \\
\hline Taxa de crescimento & $0,2578^{*}$ & $0,2785^{*}$ & $0,2653^{*}$ & $\mathbf{0 , 3 2 8 5 ^ { * }}$ \\
\hline
\end{tabular}

Fonte: Resultado da pesquisa.

Nota: Pseudossignificado empírico baseado em 99999 permutações aleatórias. * nível de significância de $1 \%$.

Ao utilizar os indicadores locais de associação espacial (Mapas Lisa) identificou-se a existência de clusters espaciais da produção e da taxa de crescimento da pecuária ao longo do Brasil. Pode-se notar, em 1990, um grande cluster com configuração espacial AA no Centro-Oeste do país, indicando que essa região concentrava espacialmente o maior rebanho do Brasil. Em 2015, por outro lado, verifica-se uma ampliação desse grande cluster para a fronteira agrícola na região Amazônica, em especial, englobando o estado 
do Mato Grosso, Pará e Rondônia. Em relação à taxa de crescimento do rebanho, destacam-se aglomerações com padrão espacial AA localizadas na região da Amazônia Legal, em especial, nos estados do Pará, Mato Grosso, Rondônia, Acre e Amazônia, o que indica uma expansão da pecuária na região. Tal dinâmica, entretanto, não está imune de externalidades negativas. De acordo com Rivero et al. (2009), a produção agropecuária, especialmente da pecuária bovina, é a principal atividade causadora de desmatamento e danos ambientais no bioma amazônico. Sendo assim, é evidente a necessidade de maiores investigações dos determinantes do crescimento da produção pecuária no país, assim como de potenciais externalidades.

Figura 2 Mapas LISA para produção bovina nas microrregiões brasileiras

a) 1990

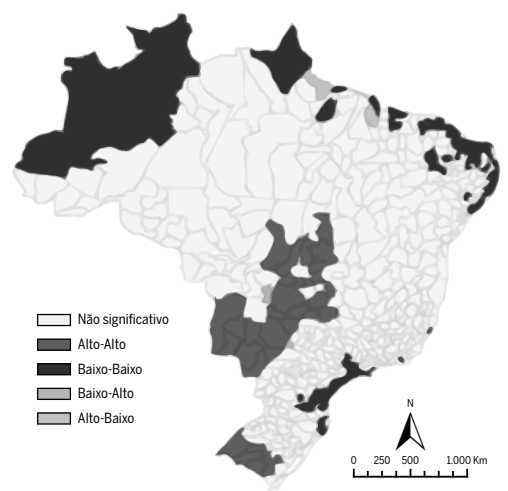

b) 2015

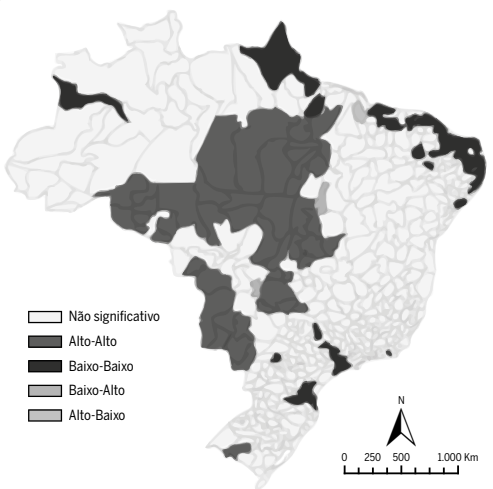

c) $1990 / 2015$

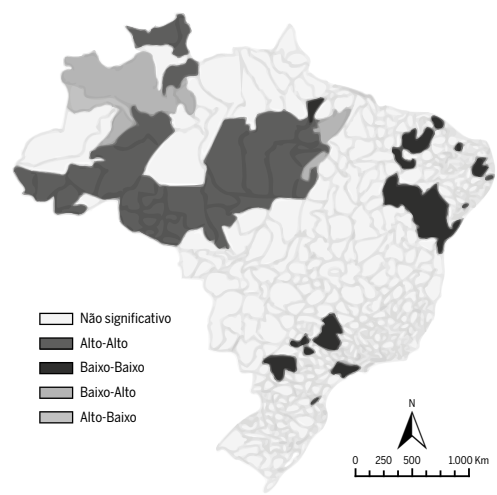

Fonte: Elaboração própria a partir do SIDRA (2017). 
Identificadas as características básicas da distribuição espacial e do avanço do rebanho no Brasil, o próximo passo será encontrar os determinantes desse avanço, com especial enfoque em suas características estruturais e na Amazônia Legal. Vale destacar a existência de dependência espacial para as variáveis dependentes, identificada por meio do I de Moran dos resíduos do painel de efeito fixo conforme destacado nas Tabelas 1A e 2A no Apêndice. Diante desse contexto, é importante a escolha da matriz de vizinhança, a qual deve respeitar certas propriedades desejáveis e certas particularidades do estudo em questão. Segundo Almeida (2012), a escolha da matriz de pesos espaciais deve ser uma matriz $W$ que capte a maior dependência espacial dos resíduos através do seguinte procedimento: a) Estima-se o modelo clássico de regressão linear, b) Testam-se os resíduos desse modelo para autocorrelação espacial, usando o I de Moran para um conjunto de matrizes $W$; c) seleciona-se a matriz de pesos espaciais que tenha gerado o mais alto valor estatisticamente significativo do $I$ de Moran, conforme pode ser observado nas Tabelas A2 e A3 no Apêndice. $O$ resultado do teste indicou que a matriz de peso espacial de três vizinhos é a mais indicada para a estimação dos modelos espaciais.

Nas Tabelas 4 e 5, têm-se os resultados para os modelos espaciais estimados ${ }^{11}$ com a técnica de dados em painel. No que se refere aos problemas econométricos, tanto no modelo de rebanho bovino quanto no modelo de densidade bovina, foi identificada a presença de heterocedasticidade. Dessa forma, todos os modelos espaciais foram estimados usando o erro padrão robusto Disccoll-Kraay, com a finalidade de controlar o problema. Para a escolha entre o modelo de efeito fixo e o de efeito aleatório, utilizou-se o teste de Hausman espacial, que rejeitou a hipótese nula de que não há diferença sistemática entre os coeficientes estimados, ${ }^{12}$ conformando a estimação por efeito fixo como a mais indicada.

Posteriormente, definiu-se o modelo espacial que melhor representa e capta a dinâmica espaçotemporal do fenômeno em estudo. Tanto a partir do critério de informação de Akaike quanto da análise residual das regressões observadas, verificou-se que o modelo Durbin Espacial (SDM)

11 Vale mencionar, por fim, que a correlação entre as variáveis utilizadas no modelo (Tabela A1 do Apêndice) não apresentaram valores que pudessem comprometer as estimações.

12 Estatística $\mathrm{Chi}^{2}$ para o modelo de rebanho bovino (Painel de dados: 936.02 SAR: 969.68 ; SDM: 960.52) e para o modelo de densidade bovina (Painel de dados: 1444.51; SAR: 1466.07; SDM: 47.51). 
é aquele com menor valor (Tabelas 4, 5 e A3 do Apêndice). Portanto, as análises posteriores serão realizadas tendo como referência esse modelo. Vale destacar que, apesar de ainda haver, em certa medida, autocorrelação espacial nos resíduos do modelo, essa se reduziu consideravelmente com a incorporação das defasagens espaciais. De qualquer maneira, é imperioso cautela ao considerar os coeficientes diante desse fato. Por outro lado, a grande quantidade de informações e anos considerados, conjuntamente ao alto grau de significância estatística de muitas das variáveis e a constância dos coeficientes em diferentes modelos, indica estabilidade estrutural para os resultados, minimizando o problema.

Os resultados das estimações apontam para a existência de um processo de desconcentração da pecuária de corte nas microrregiões brasileiras, ou seja, regiões com menor rebanho e menor densidade apresentaram taxas de crescimento superiores. $O$ fato é captado pelo sinal negativo das variáveis Rebanho.Bov $v_{i, t-1}$ e Densidade.Bov $v_{i, t-1}$ que apresentaram significância estatística no nível de $1 \%$. Desse modo, pode-se afirmar que no período de 1995 a 2016 houve avanço da pecuária bovina em microrregiões que anteriormente possuíam um rebanho relativamente menor, comprovando a hipótese levantada por diversos autores (Carvalho, 2007; Brondizio, 2009; Barona et al., 2010; Martinelli et al., 2010; Alencar et al., 2015; Domingues, 2017; e Silva et al., 2018).

Além disso, verificou-se que a taxa de crescimento do rebanho e densidade bovina é capaz de gerar transbordamentos espaciais positivos na dinâmica de crescimento de seus vizinhos próximos, fato captado pelo coeficiente espacial $\rho$, que se mostrou significativo no nível de $1 \%$ em ambos os casos. Conforme destaca Silva et al. (2012), a existência de externalidades espaciais positivas torna o setor pecuário dinâmico, em especial, devido aos spillovers de produtividade entre as regiões, o que induz o espraiamento dessa produção ao longo do território, contribuindo para a formação de clusters espaciais de alta produção e/ou produtividade. Além disso, o autor destaca iniciativas governamentais, ${ }^{13}$ além do desenvolvimento da cadeia produtiva nas regiões, como fatores adicionais que podem induzir a concentração e transbordamento espacial da pecuária de corte. Por fim, de acordo com a Nova Geografia Econômica, tal fenômeno ocorre porque

13 As principais contribuições governamentais passam por aumentos na cobertura de vacinas aplicadas contra a febre aftosa, intensificação de medidas sanitárias, apoio ao desenvolvimento e disseminação de melhoramentos genéticos, incentivo ao crédito e inspecionamento da produção. 
determinadas atividades são atraídas e aglomeradas em uma determinada localidade diante de forças atrativas (centrípetas) próprias, o que reforça a importância de se considerar o espaço e seus possíveis efeitos quando da análise da dinâmica de crescimento de determinada variável entre as regiões (Krugman, 1991), o que de fato foi confirmado pelo presente artigo para a pecuária bovina brasileira.

Para verificar a hipótese de que as regiões localizadas na Amazônia Legal apresentam uma taxa de crescimento estruturalmente maior do que as demais microrregiões brasileiras, mesmo após o controle de outros fatores relevantes, empregaram-se variáveis dicotômicas de interação espaçotemporal (descritas na subseção 3.1). Essas variáveis, referentes ao período de 1997 a $2015^{14}$ apresentaram significância estatística para todos os períodos, exceto para 1997. Portanto, as estimações indicam que a região amazônica apresentou crescimento significativamente maior em seu rebanho e na densidade bovina mesmo após, as estimações serem controladas por características estruturais capazes de influenciar suas taxas de crescimento. Dessa forma, os resultados corroboram a hipótese de que a produção bovina contribui de forma significativa para o avanço da fronteira agrícola na região da Amazônia Legal, em linha com Rivero et al. (2009), Barona et al., (2010), Alencar et al. (2015) e Silva et al. (2018).

Além disso, nota-se que a taxa de crescimento do rebanho foi entre 5,6\% a 15,68\% maior na Amazônia Legal quando comparada às demais regiões. Para a densidade bovina, o valor é ainda maior, variando de $11,11 \%$ a $21,47 \%$ de incremento. Vale destacar que a taxa de crescimento do rebanho a partir de 2003 diminuiu de ritmo, passando de 15,68\% para 7,6\%, fato que está em consonância com Assunção et al. (2015), que encontraram evidências de que a implantação do Plano de Ação para a Prevenção e Controle do Desmatamento na Amazônia Legal (PPCDAm) em 2004 reduziu significativamente o ritmo de desmatamento e, em especial, o avanço da fronteira agrícola na região Amazônica. Por outro lado, a taxa de crescimento da densidade bovina caiu relativamente menos, de $21,47 \%$ para $15,79 \%$, indicando relativa substituição do crescimento da produção por meio de expansão da área de pastagem para um crescimento mais intensivo em tecnologia, normalmente gerando menos pressões de desmatamento e, por isso, não sujeito às sanções do PPCDAm.

14 Para não cair na armadilha da variável dummy, excluiu-se a variável dicotômica para o primeiro período (1995). 
Tabela 4 Modelo de dados em painel para o rebanho bovino

\begin{tabular}{|c|c|c|c|c|c|}
\hline \multirow{2}{*}{$\begin{array}{l}\text { Variáveis } \\
\text { explicativas }\end{array}$} & \multicolumn{2}{|c|}{ Modelo de dados em painel } & \multicolumn{3}{|c|}{ Modelos espaciais de dados em painel } \\
\hline & Pooled & Efeito Fixo & $\begin{array}{r}\text { Efeito Fixo } \\
\text { SAR I }\end{array}$ & $\begin{array}{r}\text { Efeito Fixo } \\
\text { SEM II }\end{array}$ & $\begin{array}{r}\text { Efeito Fixo } \\
\text { SDM III }\end{array}$ \\
\hline Rebanho.Bov $v_{i, t-1}$ & $\begin{array}{r}-0,0052^{* *} \\
(0,002)\end{array}$ & $\begin{array}{r}-0,1845^{* * *} \\
(0,006)\end{array}$ & $\begin{array}{r}-0,1706^{* * *} \\
(0,005)\end{array}$ & $\begin{array}{r}-0,1808^{* * *} \\
(0,005)\end{array}$ & $\begin{array}{r}-0,1810^{* * *} \\
(0,005)\end{array}$ \\
\hline Produt.Insumos $_{i, t-1}$ & $\begin{array}{r}-0,0051^{*} \\
(0,003)\end{array}$ & $\begin{array}{r}-0,0001 \\
(0,006)\end{array}$ & $\begin{array}{r}-0,0054 \\
(0,005)\end{array}$ & $\begin{array}{r}-0,0016 \\
(0,005)\end{array}$ & $\begin{array}{r}-0,0007 \\
(0,089)\end{array}$ \\
\hline Areaplantio $_{i, t-1}$ & $\begin{array}{r}0,0028^{*} \\
(0,001)\end{array}$ & $\begin{array}{c}0,0097^{*} \\
(0,049)\end{array}$ & $\begin{array}{l}0,0058 \\
(0,005) \\
\end{array}$ & $\begin{array}{c}0,0089 * \\
(0,005)\end{array}$ & $\begin{array}{r}0,0072 \\
(0,005) \\
\end{array}$ \\
\hline Cred.pecuário $_{i, t-1}$ & $\begin{array}{r}0,0075^{* * *} \\
(0,001)\end{array}$ & $\begin{array}{l}0,0030 \\
(0,002)\end{array}$ & $\begin{array}{r}0,0020 * * \\
(0,002)\end{array}$ & $\begin{array}{r}0,0065^{* * *} \\
(0,002)\end{array}$ & $\begin{array}{r}0,0093^{* * *} \\
(0,018)\end{array}$ \\
\hline$\rho$ & - & - & $\begin{array}{r}0,3405^{* * *} \\
(0,013)\end{array}$ & - & $\begin{array}{r}0,3618^{* * *} \\
(0,009)\end{array}$ \\
\hline$\lambda$ & - & - & - & $\begin{array}{r}0,0195^{* * *} \\
(0,000)\end{array}$ & - \\
\hline$D A 1997_{i, t-1}$ & $\begin{array}{r}0,0883^{* * *} \\
(0,017)\end{array}$ & $\begin{array}{r}0,0505^{* *} \\
(0,022)\end{array}$ & $\begin{array}{r}0.0328^{*} \\
(0,019)\end{array}$ & $\begin{array}{l}0.0392 \\
(0,029)\end{array}$ & $\begin{array}{c}0.0261 \\
(0,019)\end{array}$ \\
\hline$D A 1999_{i, t-1}$ & $\begin{array}{r}0,1176^{* * *} \\
(0,017)\end{array}$ & $\begin{array}{r}0,0955^{* * *} \\
(0,022)\end{array}$ & $\begin{array}{r}0.0732^{* * *} \\
(0,019)\end{array}$ & $\begin{array}{r}0.0901^{* * * *} \\
(0,029)\end{array}$ & $\begin{array}{r}0.0621^{* * *} \\
(0,019)\end{array}$ \\
\hline$D A 2001_{i, t-1}$ & $\begin{array}{r}0,1431^{* * *} \\
(0,017)\end{array}$ & $\begin{array}{r}0,0142^{* * *} \\
(0,022)\end{array}$ & $\begin{array}{r}0.1079 * * * \\
(0,019)\end{array}$ & $\begin{array}{r}0.1330^{* * * *} \\
(0,029)\end{array}$ & $\begin{array}{r}0.0930 * * * \\
(0,020)\end{array}$ \\
\hline$D A 2003_{i, t-1}$ & $\begin{array}{r}0,1436^{* * *} \\
(0,017)\end{array}$ & $\begin{array}{r}0,1702^{* * *} \\
(0,022)\end{array}$ & $\begin{array}{r}0.1319 * * * \\
(0,019)\end{array}$ & $\begin{array}{r}0.1568^{* * *} \\
(0,030)\end{array}$ & $\begin{array}{r}0.1115^{* * *} \\
(0,020)\end{array}$ \\
\hline$D A 2005_{i, t-1}$ & $\begin{array}{l}0,0224 \\
(0,016)\end{array}$ & $\begin{array}{r}0,0782^{* * *} \\
(0,022)\end{array}$ & $\begin{array}{r}0.0828^{* * *} \\
(0,020)\end{array}$ & $\begin{array}{r}0.0766^{* *} \\
(0,030)\end{array}$ & $\begin{array}{r}0.0622^{* *} \\
(0,020)\end{array}$ \\
\hline$D A 2007_{i, t-1}$ & $\begin{array}{r}-0,0015 \\
(0,037)\end{array}$ & $\begin{array}{r}0,0615^{* * *} \\
(0,022)\end{array}$ & $\begin{array}{r}0.0683^{* * * *} \\
(0,020)\end{array}$ & $\begin{array}{c}0.0562^{*} \\
(0,030)\end{array}$ & $\begin{array}{r}0.0479 * * * \\
(0,020)\end{array}$ \\
\hline$D A 2009_{i, t-1}$ & $\begin{array}{r}0,0371^{* *} \\
(0,017)\end{array}$ & $\begin{array}{r}0,1036^{* * *} \\
(0,025)\end{array}$ & $\begin{array}{r}0.0934^{* * *} \\
(0,020)\end{array}$ & $\begin{array}{r}0.0922^{* * *} \\
(0,030)\end{array}$ & $\begin{array}{r}0.0716^{* * * *} \\
(0,020)\end{array}$ \\
\hline$D A 20011_{i, t-1}$ & $\begin{array}{l}0,0086 \\
(0,017)\end{array}$ & $\begin{array}{r}0,0845^{* * *} \\
(0,022)\end{array}$ & $\begin{array}{r}0.0843^{* * *} \\
(0,020)\end{array}$ & $\begin{array}{r}0.0753^{* *} \\
(0,030)\end{array}$ & $\begin{array}{r}0.0610^{* * * *} \\
(0,020)\end{array}$ \\
\hline$D A 2013_{i, t-1}$ & $\begin{array}{l}0,0086 \\
(0,017) \\
\end{array}$ & $\begin{array}{r}0,0839 * * * \\
(0,022)\end{array}$ & $\begin{array}{r}0.0867^{* * *} \\
(0,020)\end{array}$ & $\begin{array}{r}0.0757^{* *} \\
(0,030)\end{array}$ & $\begin{array}{r}0.0570 * * * \\
(0,021)\end{array}$ \\
\hline$D A 2015_{i, t-1}$ & $\begin{array}{r}-0,0084 \\
(0,017) \\
\end{array}$ & $\begin{array}{r}0,0691 \\
(0,022) \\
\end{array}$ & $\begin{array}{r}0.0796 * * * \\
(0,020)\end{array}$ & $\begin{array}{r}0.0661^{* *} \\
(0,030)\end{array}$ & $\begin{array}{r}0.0493^{* *} \\
(0,021)\end{array}$ \\
\hline Outilier Positivo ${ }_{i, t-1}$ & $\begin{array}{r}0,0199 * * * \\
(0,007) \\
\end{array}$ & $\begin{array}{r}0,1457 \\
(0,010) \\
\end{array}$ & $\begin{array}{r}0.0135 \\
(0,009) \\
\end{array}$ & $\begin{array}{r}0.0134 \\
(0,008) \\
\end{array}$ & $\begin{array}{r}0.0124 \\
(0,009) \\
\end{array}$ \\
\hline Outilier Negativo $_{{ }_{i, t-1}}$ & $\begin{array}{r}-0,0366^{* * *} \\
(0,007)\end{array}$ & $\begin{array}{r}-0,0692^{* * *} \\
(0,009)\end{array}$ & $\begin{array}{r}-0.0502^{* * *} \\
(0,008)\end{array}$ & $\begin{array}{r}-0.0394^{* * *} \\
(0,009)\end{array}$ & $\begin{array}{r}-0.0498^{* * *} \\
(0,008)\end{array}$ \\
\hline
\end{tabular}


Tabela 4 (continuação)

\begin{tabular}{|c|c|c|c|c|c|}
\hline \multirow{2}{*}{$\begin{array}{l}\text { Variáveis } \\
\text { explicativas }\end{array}$} & \multicolumn{2}{|c|}{ Modelo de dados em painel } & \multicolumn{3}{|c|}{ Modelos espaciais de dados em painel } \\
\hline & Pooled & Efeito Fixo & $\begin{array}{r}\text { Efeito Fixo } \\
\text { SAR I }\end{array}$ & $\begin{array}{r}\text { Efeito Fixo } \\
\text { SEM II }\end{array}$ & $\begin{array}{r}\text { Efeito Fixo } \\
\text { SDM III }\end{array}$ \\
\hline WRebanho.Bov $v_{\cdot i t-1}$ & - & - & - & - & $\begin{array}{r}0,0563^{* * *} \\
(0,009)\end{array}$ \\
\hline WProdut.Insumos $_{i, t-1}$ & - & - & - & - & $\begin{array}{r}0,0033 \\
(0,009)\end{array}$ \\
\hline WAreaplantio $_{i, t-1}$ & - & - & - & - & $\begin{array}{r}-0,0031 \\
(0,007)\end{array}$ \\
\hline WCred.pecuário $_{i, t-1}$ & - & - & - & - & $\begin{array}{r}-0,0098^{* * *} \\
(0,003)\end{array}$ \\
\hline Crit. Inf. Akaike & $-4443,37$ & $-5856,36$ & $-6446,37$ & $-6465,99$ & $-6481,08$ \\
\hline
\end{tabular}

Fonte: Estimação dos autores com os dados da pesquisa.

Nota: Os valores entre parênteses referem-se ao desvio padrão. *** Significativo a um nível de significância de 1\%; ** Significativo a um nível de significância de 5\% * Significativo a um nível de significância de $10 \%$. As variáveis outliers se referem a pontos de alavancagem detectados na AEDE.

Tabela 5 Modelo de dados em painel para a densidade bovina

\begin{tabular}{|c|c|c|c|c|c|}
\hline \multirow{2}{*}{$\begin{array}{l}\text { Variáveis } \\
\text { explicativas }\end{array}$} & \multicolumn{2}{|c|}{ Modelo de dados em painel } & \multicolumn{3}{|c|}{ Modelos espaciais de dados em painel } \\
\hline & Pooled & Efeito Fixo & $\begin{array}{r}\text { Efeito Fixo } \\
\text { SAR I }\end{array}$ & $\begin{array}{r}\text { Efeito Fixo } \\
\text { SEM II }\end{array}$ & $\begin{array}{r}\text { Efeito Fixo } \\
\text { SDM III }\end{array}$ \\
\hline Densidade.Bov ${ }_{{ }_{\mathrm{i}, \mathrm{i}-1}}$ & $\begin{array}{r}-0,0092^{* * *} \\
(0,002)\end{array}$ & $\begin{array}{r}-0,3136^{* * *} \\
(0,008)\end{array}$ & $\begin{array}{r}-0,2879 * * * \\
(0,005)\end{array}$ & $\begin{array}{r}-0,3093^{* * *} \\
(0,008)\end{array}$ & $\begin{array}{r}-0,3089 * * * \\
(0,008)\end{array}$ \\
\hline Produt.Insumos ${ }_{\mathrm{i}, \mathrm{t}-1}$ & $\begin{array}{r}-0,0043^{*} \\
(0,003)\end{array}$ & $\begin{array}{r}-0,0094 \\
(0,005)\end{array}$ & $\begin{array}{r}-0,0068 \\
(0,005)\end{array}$ & $\begin{array}{r}-0,0034 \\
(0,005)\end{array}$ & $\begin{array}{r}-0,0026 \\
(0,089)\end{array}$ \\
\hline Areaplantio $_{\mathrm{i}, \mathrm{t}-1}$ & $\begin{array}{l}0,0019 \\
(0,001)\end{array}$ & $\begin{array}{r}0,0200 * * * \\
(0,004)\end{array}$ & $\begin{array}{r}-0,0214^{* * *} \\
(0,004)\end{array}$ & $\begin{array}{r}0,0215^{* * *} \\
(0,004)\end{array}$ & $\begin{array}{r}0,0228^{* * *} \\
(0,005)\end{array}$ \\
\hline Cred.pecuário ${ }_{\mathrm{i}, \mathrm{t}-1}$ & $\begin{array}{r}0,0080^{* * *} \\
(0,008)\end{array}$ & $\begin{array}{r}0,0064^{* * *} \\
(0,005)\end{array}$ & $\begin{array}{r}0,0074^{* * *} \\
(0,002)\end{array}$ & $\begin{array}{r}0,0078^{* * *} \\
(0,002)\end{array}$ & $\begin{array}{r}0,0077^{* * *} \\
(0,026)\end{array}$ \\
\hline$\rho$ & - & - & $\begin{array}{r}0,3200^{* * *} \\
(0,013)\end{array}$ & - & $\begin{array}{r}0,3522^{* * *} \\
(0,013)\end{array}$ \\
\hline$\lambda$ & - & - & - & $\begin{array}{r}0,3513^{* * *} \\
(0,013)\end{array}$ & - \\
\hline$D A 1997_{\mathrm{i}, \mathrm{t}-1}$ & $\begin{array}{r}0,0738^{* * *} \\
(0,017)\end{array}$ & $\begin{array}{r}0,0562^{* *} \\
(0,021)\end{array}$ & $\begin{array}{r}0.0389 * * \\
(0,019)\end{array}$ & $\begin{array}{l}0.0462 \\
(0,028)\end{array}$ & $\begin{array}{l}0.0300 \\
(0,019)\end{array}$ \\
\hline$D A 1999_{\mathrm{i}, \mathrm{t}-1}$ & $\begin{array}{r}0,1036^{* * *} \\
(0,017)\end{array}$ & $\begin{array}{r}0,1155^{* * *} \\
(0,021)\end{array}$ & $\begin{array}{r}0.0930 * * * \\
(0,019)\end{array}$ & $\begin{array}{r}0.1110 * * * \\
(0,028)\end{array}$ & $\begin{array}{r}0.0736^{* * *} \\
(0,019)\end{array}$ \\
\hline
\end{tabular}


Tabela 5 (continuação)

\begin{tabular}{|c|c|c|c|c|c|}
\hline \multirow{2}{*}{$\begin{array}{l}\text { Variáveis } \\
\text { explicativas }\end{array}$} & \multicolumn{2}{|c|}{ Modelo de dados em painel } & \multicolumn{3}{|c|}{ Modelos espaciais de dados em painel } \\
\hline & Pooled & Efeito Fixo & $\begin{array}{r}\text { Efeito Fixo } \\
\text { SAR I }\end{array}$ & $\begin{array}{r}\text { Efeito Fixo } \\
\text { SEM II }\end{array}$ & $\begin{array}{r}\text { Efeito Fixo } \\
\text { SDM III }\end{array}$ \\
\hline$D A 2001_{\mathrm{i}, \mathrm{t}-1}$ & $\begin{array}{r}0,1291^{* * *} \\
(0,017)\end{array}$ & $\begin{array}{r}0,1794^{* * *} \\
(0,021)\end{array}$ & $\begin{array}{r}0.1430^{* * *} \\
(0,019)\end{array}$ & $\begin{array}{r}0.1710^{* * *} \\
(0,028)\end{array}$ & $\begin{array}{r}0.1180^{* * * *} \\
(0,019)\end{array}$ \\
\hline$D A 2003_{\mathrm{i}, \mathrm{t}-1}$ & $\begin{array}{r}0,1301^{* * *} \\
(0,017)\end{array}$ & $\begin{array}{r}0,2262^{* * * *} \\
(0,021)\end{array}$ & $\begin{array}{r}0.1847^{* * * *} \\
(0,019)\end{array}$ & $\begin{array}{r}0.2147^{* * * *} \\
(0,028)\end{array}$ & $\begin{array}{r}0.1500^{* * *} \\
(0,019)\end{array}$ \\
\hline$D A 2005_{i, t-1}$ & $\begin{array}{l}0,0091 \\
(0,017)\end{array}$ & $\begin{array}{r}0,1573^{* * *} \\
(0,021)\end{array}$ & $\begin{array}{r}0.1540^{* * *} \\
(0,019)\end{array}$ & $\begin{array}{r}0.1579 * * * \\
(0,028)\end{array}$ & $\begin{array}{r}0.1143^{* * * *} \\
(0,020)\end{array}$ \\
\hline$D A 2007_{i, t-1}$ & $\begin{array}{r}-0,0146 \\
(0,017)\end{array}$ & $\begin{array}{r}0,1432^{* * * *} \\
(0,022)\end{array}$ & $\begin{array}{r}0.1417^{* * * *} \\
(0,019)\end{array}$ & $\begin{array}{r}0.1414^{* * * *} \\
(0,028)\end{array}$ & $\begin{array}{r}0.1021^{* * * *} \\
(0,020)\end{array}$ \\
\hline$D A 2009_{i, t-1}$ & $\begin{array}{l}0,0242 \\
(0,017)\end{array}$ & $\begin{array}{r}0,1867^{* * *} \\
(0,022)\end{array}$ & $\begin{array}{r}0.1690 * * * \\
(0,019)\end{array}$ & $\begin{array}{r}0.1795^{* * * *} \\
(0,028)\end{array}$ & $\begin{array}{r}0.1276^{* * *} \\
(0,020)\end{array}$ \\
\hline$D A 20011_{i, t-1}$ & $\begin{array}{r}-0,0041 \\
(0,017) \\
\end{array}$ & $\begin{array}{r}0,1744^{* * *} \\
(0,022)\end{array}$ & $\begin{array}{r}0.1654^{* * *} \\
(0,019)\end{array}$ & $\begin{array}{r}0.1695^{* * *} \\
(0,029) \\
\end{array}$ & $\begin{array}{r}0.1207^{* * *} \\
(0,020)\end{array}$ \\
\hline$D A 2013_{\mathrm{i}, t-1}$ & $\begin{array}{r}-0,0036 \\
(0,017) \\
\end{array}$ & $\begin{array}{r}0,1808^{* * *} \\
(0,022) \\
\end{array}$ & $\begin{array}{r}0.1741^{* * *} \\
(0,020)\end{array}$ & $\begin{array}{r}0.1757^{* * *} \\
(0,029) \\
\end{array}$ & $\begin{array}{r}0.1228^{* * *} \\
(0,021)\end{array}$ \\
\hline$D A 2015_{i, t-1}$ & $\begin{array}{r}-0,0207 \\
(0,017)\end{array}$ & $\begin{array}{r}0,1709 * * * \\
(0,022)\end{array}$ & $\begin{array}{r}0.1709 * * * \\
(0,020)\end{array}$ & $\begin{array}{r}0.1703^{* * * *} \\
(0,029)\end{array}$ & $\begin{array}{r}0.1187^{* * *} \\
(0,021)\end{array}$ \\
\hline Outilier Positivo $_{\cdot, t,-1}$ & $\begin{array}{r}0,0155^{* *} \\
(0,007)\end{array}$ & $\begin{array}{r}0,0147 \\
(0,010) \\
\end{array}$ & $\begin{array}{r}0.0137 \\
(0,0098) \\
\end{array}$ & $\begin{array}{r}0.0138 \\
(0,009) \\
\end{array}$ & $\begin{array}{r}0.0126 \\
(0,009) \\
\end{array}$ \\
\hline Outilier Negativo ${ }_{\cdot i, t-1}$ & $\begin{array}{r}-0,0380^{* * * *} \\
(0,007)\end{array}$ & $\begin{array}{r}-0,0689^{* * *} \\
(0,009)\end{array}$ & $\begin{array}{r}-0.0510 * * * \\
(0,009)\end{array}$ & $\begin{array}{r}-0.0415^{* * *} \\
(0,008)\end{array}$ & $\begin{array}{r}-0.0506^{* * * *} \\
(0,008) \\
\end{array}$ \\
\hline WDensidade.Bov $v_{i, t-1}$ & - & - & - & - & $\begin{array}{r}0,0924^{* * * *} \\
(0,009)\end{array}$ \\
\hline WProdut.Insumos $_{i, t-1}$ & - & - & - & - & $\begin{array}{l}0,0153^{*} \\
(0,008)\end{array}$ \\
\hline WAreaplantio $_{i, t-1}$ & - & - & - & - & $\begin{array}{r}-0,0059 \\
(0,006) \\
\end{array}$ \\
\hline WCred.pecuário $_{i, t-1}$ & - & - & - & - & $\begin{array}{r}-0,0036 \\
(0,003)\end{array}$ \\
\hline Crit. Inf. Akaike & $-4454,03$ & $-6333,02$ & $-6873,61$ & $-6901,9$ & $-6918,75$ \\
\hline
\end{tabular}

Fonte: Estimação dos autores com os dados da pesquisa.

Nota: Os valores entre parênteses referem-se ao desvio padrão. ${ }^{* *}$ Significativo a um nível de significância de 1\%; ** Significativo a um nível de significância de 5\% * Significativo a um nível de significância de $10 \%$. As variáveis outliers se referem a pontos de alavancagem detectados na AEDE.

O montante de crédito pecuário destinado à microrregião também se mostrou significativo em nível de $1 \%$ tanto para o rebanho bovino quanto para 
a densidade, indicando que quando há aumento no crédito destinado à pecuária, o resultado é um aumento na taxa de crescimento do rebanho/ densidade na região receptora. Conforme destaca Macedo (2005), o crédito possibilita desde a compra de melhores insumos e maquinários até o custeio fazenda, fatos que podem explicar sua relação com o crescimento do rebanho/densidade. A sua versão defasada espacialmente foi negativamente significativa a $1 \%$, isto é, o aumento do crédito pecuário para determinada microrregião transborda negativamente para os vizinhos. Apoiando-se na Nova Geografia Econômica, pode-se concluir que o aumento do crédito pecuário para uma região tende a aumentar a sua respectiva taxa de crescimento, potencialmente atraindo as atividades pecuárias para si, afetando negativamente seus vizinhos próximos (Krugman, 1991). A área plantada e o fator de produtividade dos insumos não apresentam significância estatística para explicar o crescimento do rebanho, tanto em sua versão local quanto defasada espacialmente.

Em relação à densidade bovina, a área plantada está positivamente relacionada com a taxa de crescimento, isto é, quando há um aumento na área destinada ao plantio em determinada região, observa-se aumento na taxa de crescimento da densidade bovina com significância estatística de 1\%. Esse fato pode ser uma evidência indireta de que o aumento da área plantada incentiva a intensificação da pecuária dada a eventual competitividade no uso do solo entre área plantada e pastagem. Por outro lado, a área total destinada ao plantio das regiões vizinhas não sofre influência dessa variável. O fator de produtividade dos insumos também apresentou significância estatística positiva de $10 \%$ em sua versão defasada espacialmente. Desse modo, o nível de produtividade apresentado pela soja, milho e cana-de-açúcar pode afetar a taxa de crescimento da densidade bovina nas microrregiões vizinhas. Tal evidência corrobora autores como Martinelli e Filoso (2008), Mendonça et al. (2016) e Carvalho e Zen (2017), que enfatizam a importância de tais culturas na nutrição bovina, possivelmente influenciando o crescimento do rebanho. De qualquer forma, a coexistência de modos intensivos e extensivos de produção ao longo do país, com diversos graus de utilização de insumos agrícolas, pode ser uma das razões da não significância dessa variável para o rebanho como também da sua significância estatística na sua versão defasada para a densidade bovina. 


\section{Considerações finais}

A motivação inicial deste trabalho foi entender a dinâmica espaçotemporal da produção bovina brasileira com especial enfoque para seu avanço na Amazônia Legal. Como objetivos secundários, pode-se mencionar a busca por padrões espaciais e a busca por clusters significativos entre as regiões brasileiras. De maneira geral, encontram-se evidências de que microrregiões com grande rebanho bovino estão circundadas por regiões com valores similares, com as regiões Norte e Centro-Oeste concentrando os principais clusters AA da produção bovina brasileira. Além disso, verificou-se um deslocamento desse agrupamento, que anteriormente majoritariamente estava concentrado no Centro-Oeste, em direção à Amazônia, especialmente para os estados de Rondônia, Pará e Mato Grosso, refletindo, em grande medida, o avanço da fronteira agrícola brasileira.

Com relação às estimações, a partir da detecção de dependência espacial, tornara-se necessária a utilização de modelos espaciais. O modelo Durbin espacial (SDM) apresentou o melhor ajuste tanto a partir dos critérios de seleção de Akaike quanto da análise dos resíduos dos modelos. Os resultados indicaram que o rebanho e a densidade bovina apresentaram taxas de crescimento consideravelmente mais elevadas para a Amazônia Legal, evidenciando um processo de expansão da produção/densidade bovina ao longo da região. Entre as variáveis estruturais, o montante de crédito pecuário se mostrou importante para explicar a taxa de crescimento da pecuária de corte, com efeito positivo na região de referência, e negativo para os vizinhos. O fator de produtividade dos insumos apresentou significância estatística apenas em sua versão defasada espacialmente para a densidade bovina, indicando um transbordamento espacial negativo. A área total destinada ao plantio apresentou significância estatística para a densidade bovina, indicando que o aumento na área plantada está relacionado ao aumento na densidade bovina.

Também se identificou a existência de transbordamentos espaciais positivos para o rebanho e para a densidade bovina, captada pelo coeficiente de autocorrelação espacial, indicando a presença de externalidades positivas para a produção. Esse resultado contribui para a literatura no sentido de evidenciar a importância das externalidades positivas na pecuária bovina brasileira, o que possivelmente pode atuar como indutor de aumento da produção e de concentração espacial. 
De maneira geral, as estimações confirmaram que o rebanho e a densidade bovina cresceram de maneira mais acelerada nas regiões amazônicas, mesmo após a inclusão de controles estruturais. Esse fato, portanto, corrobora a hipótese levantada pelo presente artigo, a qual também foi verificada preliminarmente na análise exploratória de dados, isto é, que a produção bovina brasileira tem crescido de maneira mais intensa na Amazônia Legal. Vale destacar que um ponto não abordado diretamente pelo presente artigo, mas que certamente merece atenção, é o possível impacto ambiental gerado pelo avanço da pecuária na Amazônia, especialmente em termos de desmatamento desse bioma. Sendo assim, recomenda-se como trabalho futuro, a verificação da magnitude dessa externalidade negativa, assim como de outras, causada pela expansão do rebanho bovino na região.

\section{Referências}

ALENCAR, A.; PEREIRA, C.; CASTRO, I.; CARDOSO, A. Desmatamento nos Assentamentos da Amazônia: histórico, tendências e oportunidades. Brasília, DF: IPAM, 2015.

ALMEIDA, E. Econometria espacial aplicada. Campinas: Alinea, 2012. 498 p.

ASSAD, E. D. Amazônia Legal: propostas para uma exploração agrícola sustentável (sumário executivo). Relatório Técnico - FGVAgro, 2016

ASSUNÇÃO, J; GANDOUR, C; ROCHA, R. Deforestation slowdown in the Legal Amazon: Prices or Policies? Environment and Development Economics, 20(6), 697-722, 2015.

BARONA, E; RAMANKUTTY, N; HYMAN, G; COMMES, O. The role of pasture and soybean in deforestation of the Brazilian. Environmental Research Letters, 5, 024002 (9pp), 2010.

BRONDIZIO, E. S. Análise inter-regional de mudança do uso da terra na Amazônia. In: MORAN, E. F.; OSTROM, E. (Org.). Ecossistemas Florestais: interação homem-ambiente. São Paulo: EDUSP, p. 289-326, 2009.

CARVALHO, T. B. Estudo da elasticidade-renda da demanda de carne bovina, suina e de frango no Brasil. Tese (Doutorado) - Universidade de São Paulo, 2007.

CARVALHO, T. B.; ZEN, Sérgio. A cadeia de pecuária de corte no Brasil: evolução e tendências. Revista iPecege, v. 3, n. 1, p. 85-99, 2017.

CEZAR, I. M.; QUEIROZ, H. P.; THIAGO, L. R. L. S. Sistemas de produção de gado de corte no Brasil: uma descrição com ênfase no regime alimentar e no abate. Campo Grande, MS: Embrapa Gado de Corte, 2005.

DIAS FILHO, M. B. Os desafios da produção animal em pastagens na fronteira agrícola brasileira. Revista brasileira de Zootecnia, v. 40, n. Suplemento Especial, p. 243-252, 2011.

DOMINGUES, M. S.; BERMANN, C.; SIDNEIDE, S.; A produção da soja no Brasil e sua relação com o desmatamento na Amazônia. Revista Presença Geográfica, v. 1, n. 1, 2017. 
FEARNSIDE, P. M. Desmatamento na Amazônia brasileira: história, índices e consequências. Megadiversidade, v. 1, n. 1, p. 113-123, 2005.

FILHO, R. A. M. Sistemas de terminação em confinamento: perspectivas para dinamização da cadeia produtiva da carne bovina em Minas Gerais. Revista Brasileira de Economia, v. 55, n. 1, 2001.

KAMALI, F. P.; LINDEN, A. V. D.; MEUWISSEN, M. C. Environmental and economic performance of beef farming systems with different feeding strategies in southern Brazil. Agricultural Systems, v. 146, p. 70-79, 2016.

KRUGMAN, P. Geography and trade. Cambridge, MA: MIT Press, 1991.

MACEDO, L. O. B. Modernização da pecuária de corte bovina no Brasil e a importância do crédito rural. Agroanalysis, Rio de Janeiro, v. 25, n. 6, p. 35-36, 2005.

MARTINELLI, L. A.; FILOSO, S. Expansion of sugarcane ethanol production in Brazil: environmental and social challenges. Ecological Applications, v. 18, n. 4, p. 885-898, 2008.

MARTINELLI, L. A.; NAYLOR, R.; VITOUSEK, P. M.; MOUTINHO, P. Agriculture in Brazil: impacts, costs, and opportunities for a sustainable future. Current Opinion in Environmental Sustainability, v. 2, n. 5-6, p. 431-438, 2010.

MCMANUS, C.; BARCELLOS, J. O. J; FORMENTON, B. K.; HERMUCHE, P. M. Dynamics of cattle production in Brazil. PloS one, v. 11, n. 1, 2016.

MENDONÇA, F. S.; VAZ, R. Z.; COSTA, A. D. Fatores que afetam o bem-estar de bovinos durante o período pré-abate. Archivos de Zootecnia, v. 65, n. 250, p. 279-287, 2016.

NASCIMENTO, F. Desmatamento zero na Amazônia: como e por que chegar lá. Greenpeace, 2017.

RIVERO, S.; ALMEIDA, O.; ÁVILA, S.; OLIVEIRA, W. Pecuária e desmatamento: uma análise das principais causas diretas do desmatamento na Amazônia. Nova Economia, Belo Horizonte, v. 19, n. 1, p. 41-66, 2009.

RODRIGUES, M.; SILVA, D. C.; JUNIOR, W. C. A redução do desmatamento na Amazônia: o papel dos mecanismos institucionais. Revista de Administração e Negócios da Amazônia, v. 10, n. 1, p. 108-123, 2018.

SILVA, J. C.; SOUZA, E. C.; MARTINS, H. E. P. Produção agropecuária em municípios de Minas Gerais (1996-2006): padrões de distribuição, especialização e associação espacial. Revista de Economia e Sociologia Rural, v. 50, n. 2, p. 333-349, 2012.

SILVA, M. M.; OLIVEIRA, F. A.; SANTANA, A. C. Mudanças socioambientais no uso da terra em Altamira, Amazônia Oriental. Novos Cadernos NAEA, v. 20, n. 3, 2018.

TEIXEIRA, C.;HESPANHOL, A. N. A região Centro-Oeste no contexto das mudanças agrícolas ocorridas no período após 1960. Revista da Associação de Geógrafos Brasileiros, p. 52, 2006.

WOOLDRIDGE, J. M. Econometric analysis of cross section and panel data. Cambridge: The MIT Press, 2002. 


\section{Sobre os autores}

Adirson Maciel de Freitas Junior - adirson52@gmail.com Universidade de São Paulo, Campus ESALQ, Piracicaba, SP, Brasil. ORCID: https://orcid.org/0000-0003-3868-0235.

Pedro Henrique Batista de Barros - pedrohbarros@usp.br

Departamento de Economia da Faculdade de Economia e Administração, Universidade de São Paulo, São Paulo, SP, Brasil. ORCID: https://orcid.org/0000-0002-7968-0197.

\section{Sobre 0 artigo}

Recebido em 19 de outubro de 2018. Aprovado em 12 de fevereiro de 2020. 


\section{APÊNDICE}

Tabela A1 Correlação variáveis microrregiões Brasil de 1993 a 2017 - 6.138 observações

\begin{tabular}{ll|r|r|r|r|r|r|r|r|r}
\hline & Correlação & Y1 & Y2 & X1 & X2 & X3 & X4 & X5 & X6 & F1 \\
\hline Y1 & Reb.Bov & 1,000 & - & - & - & - & - & - & - & - \\
\hline Y2 & Reb.Bov.Km ${ }^{2}$ & 0,616 & 1,000 & - & - & - & - & - & - & - \\
\hline X1 & Produ. Total* & 0,579 & 0,4541 & 1,000 & - & - & - & - & - & - \\
\hline X2 & Areaplan & 0,648 & 0,424 & 0,8439 & 1,000 & - & - & - & - & - \\
\hline X3 & Credpec & 0,689 & 0,559 & 0,469 & 0,514 & 1,000 & - & - & - & - \\
\hline X4 & Prod. Milho & 0,297 & 0,215 & 0,447 & 0,323 & 0,218 & 1,000 & - & - & - \\
\hline X5 & Prod. Soja & 0,550 & 0,377 & 0,616 & 0,587 & 0,443 & 0,333 & 1,000 & - & - \\
\hline X6 & Prod. Cana & 0,472 & 0,349 & 0,525 & 0,532 & 0,464 & 0,214 & 0,516 & 1,000 & - \\
\hline F1 & Prod. Insu & 0,592 & 0,423 & 0,701 & 0,643 & 0,512 & 0,609 & 0,826 & 0,781 & 1,000 \\
\hline
\end{tabular}

Fonte: Resultado da pesquisa.

Nota: $($ Prod. $)=($ Produtividade); $($ Produ. $)=($ Produção); *Produção total em toneladas das culturas disponíveis pesquisa anual municipal 2019 - SIDRA.

Tabela A2 Painel de efeitos fixos (Sem componente espacial) - I de Moran dos resíduos do rebanho bovino de corte das microrregiões brasileiras

\begin{tabular}{l|rrrrrr}
\hline \multirow{2}{*}{ Ano } & \multicolumn{3}{r}{} & \multicolumn{2}{r}{ Matrizes espaciais } \\
\cline { 2 - 6 } & K3 & K4 & K5 & K7 & K10 \\
\hline 1995 & $0.408^{*}$ & $0.403^{*}$ & $0.400^{*}$ & $0.351^{*}$ & $0.321^{*}$ \\
\hline 1997 & $0.665^{*}$ & $0.644^{*}$ & $0.631^{*}$ & $0.587^{*}$ & $0.558^{*}$ \\
\hline 1999 & $0.585^{*}$ & $0.582^{*}$ & $0.570^{*}$ & $0.532^{*}$ & $0.486^{*}$ \\
\hline 2001 & $0.576^{*}$ & $0.582^{*}$ & $0.565^{*}$ & $0.524^{*}$ & $0.481^{*}$ \\
\hline 2003 & $0.589^{*}$ & $0.571^{*}$ & $0.548^{*}$ & $0.509^{*}$ & $0.456^{*}$ \\
\hline 2005 & $0.510^{*}$ & $0.510^{*}$ & $0.489^{*}$ & $0.451^{*}$ & $0.408^{*}$ \\
\hline 2007 & $0.554^{*}$ & $0.556^{*}$ & $0.534^{*}$ & $0.480^{*}$ & $0.431^{*}$ \\
\hline 2011 & $0.486^{*}$ & $0.452^{*}$ & $0.447^{*}$ & $0.413^{*}$ & $0.371^{*}$ \\
\hline 2013 & $0.609^{*}$ & $0.589^{*}$ & $0.570^{*}$ & $0.520^{*}$ & $0.478^{*}$ \\
\hline 2015 & $0.581^{*}$ & $0.560^{*}$ & $0.554^{*}$ & $0.503^{*}$ & $0.454^{*}$ \\
\hline
\end{tabular}

Fonte: Resultado da pesquisa.

Nota: * Significante ao nível de $1 \%$. 
Tabela A3 Painel de efeitos fixos (Sem componente espacial) - I de Moran dos resíduos da densidade bovina nas microrregiões brasileiras

\begin{tabular}{l|rrrrrr}
\hline \multirow{2}{*}{ Ano } & \multicolumn{3}{r}{} & \multicolumn{2}{r}{ Matrizes espaciais } \\
\cline { 2 - 6 } & K3 & K4 & K5 & K7 & K10 \\
\hline 1995 & $0.565^{*}$ & $0.560^{*}$ & $0.551^{*}$ & $0.502^{*}$ & $0.470^{*}$ \\
\hline 1997 & $0.664^{*}$ & $0.652^{*}$ & $0.635^{*}$ & $0.589^{*}$ & $0.547^{*}$ \\
\hline 1999 & $0.627^{*}$ & $0.628^{*}$ & $0.607^{*}$ & $0.566^{*}$ & $0.512^{*}$ \\
\hline 2001 & $0.648^{*}$ & $0.643^{*}$ & $0.616^{*}$ & $0.569^{*}$ & $0.504^{*}$ \\
\hline 2003 & $0.642^{*}$ & $0.630^{*}$ & $0.601^{*}$ & $0.550^{*}$ & $0.489^{*}$ \\
\hline 2005 & $0.615^{*}$ & $0.589^{*}$ & $0.573^{*}$ & $0.532^{*}$ & $0.484^{*}$ \\
\hline 2009 & $0.611^{*}$ & $0.619^{*}$ & $0.596^{*}$ & $0.541^{*}$ & $0.489^{*}$ \\
\hline 2011 & $0.602^{*}$ & $0.581^{*}$ & $0.564^{*}$ & $0.520^{*}$ & $0.459^{*}$ \\
\hline 2013 & $0.617^{*}$ & $0.608^{*}$ & $0.574^{*}$ & $0.523^{*}$ & $0.465^{*}$ \\
\hline 2015 & $0.642^{*}$ & $0.632^{*}$ & $0.605^{*}$ & $0.552^{*}$ & $0.489^{*}$ \\
\hline
\end{tabular}

Fonte: Resultado da pesquisa.

Nota: * Significante ao nível de $1 \%$.

Tabela A4 I de Moran dos resíduos das microrregiões brasileiras por modelo

\begin{tabular}{lrrrrrrr}
\hline \multirow{2}{*}{ Ano } & \multicolumn{4}{r|r}{ Rebanho bovino de corte } & \multicolumn{3}{|r}{ Rebanho bovino de corte por km } \\
\cline { 2 - 7 } & SAR & SEM & SDM & SAR & SEM & SDM \\
\hline 1995 & $0.205^{*}$ & $0.239^{*}$ & $0.228^{*}$ & $0.232^{*}$ & $0.188^{*}$ & $0.222^{*}$ \\
\hline 1997 & $0.368^{*}$ & $0.386^{*}$ & $0.368^{*}$ & $0.384^{*}$ & $0.362^{*}$ & $0.373^{*}$ \\
\hline 1999 & $0.345^{*}$ & $0.305^{*}$ & $0.310^{*}$ & $0.177^{*}$ & $0.226^{*}$ & $0.184^{*}$ \\
\hline 2001 & $0.178^{*}$ & $0.130^{*}$ & $0.144^{*}$ & $0.137^{*}$ & $0.191^{*}$ & $0.147^{*}$ \\
\hline 2003 & $0.100^{*}$ & $0.113^{*}$ & $0.111^{*}$ & $0.121^{*}$ & $0.114^{*}$ & $0.121^{*}$ \\
\hline 2005 & $0.140^{*}$ & $0.150^{*}$ & $0.142^{*}$ & $0.220^{*}$ & $0.174^{*}$ & $0.22^{*}$ \\
\hline 2007 & $0.155^{*}$ & $0.154^{*}$ & $0.151^{*}$ & $0.221^{*}$ & $0.246^{*}$ & $0.220^{*}$ \\
\hline 2009 & $0.189^{*}$ & $0.199^{*}$ & $0.197^{*}$ & $0.190^{*}$ & $0.196^{*}$ & $0.188^{*}$ \\
\hline 2011 & $0.326^{*}$ & $0.327^{*}$ & $0.319^{*}$ & $0.253^{*}$ & $0.263^{*}$ & $0.251^{*}$ \\
\hline 2013 & $0.300^{*}$ & $0.259^{*}$ & $0.261^{*}$ & $0.131^{*}$ & $0.189^{*}$ & $0.136^{*}$ \\
\hline
\end{tabular}

Fonte: Resultado da pesquisa.

Nota: ${ }^{*}$ Significante ao nível de $1 \%$. 